\title{
LA COMPLEJIDAD DEL RÉGIMEN \\ INTERNACIONAL Y LA GOBERNANZA \\ REGIONAL: EVIDENCIA DE LATINOAMÉRICA
}

LAURA Gómez-Mera

\section{INTRODUCGIÓN}

A ÚlTimAS FECHAS, HA SOBREVENIDO una expansión sin precedentes en los acuerdos de cooperación, que incluyen una vasta gama de temas de relaciones internacionales, como comercio, dinero y finanzas, medio ambiente, energía y seguridad. La proliferación de acuerdos que se superponen (overlapping) y de organizaciones, y la densidad en los regímenes internacionales que de ahí resulta, ha causado interés entre los especialistas de relaciones internacionales y el derecho internacional. Esta discusión atiende cada vez más las consecuencias de la creciente complejidad de régimen sobre la política y la efectividad de la gobernanza global. ¿Cómo es que la superposición y la interacción entre varias instituciones en el área de un solo tema afectan la política internacional? ¿En qué medida y de qué manera la complejidad del régimen internacional influye en las estrategias y determinaciones de los Estados y otros actores? Y, por fin, ¿facilita o afecta la complejidad de los regímenes a las metas de la cooperación internacional?

Este artículo trata sobre estas cuestiones teóricas enfocándose en el caso de los acuerdos del comercio y la cooperación económica en Latinoamérica. Desde la década de 1990, países de la región y el Caribe han buscado una estrategia en varios niveles para la liberalización del comercio, lo cual ha resultado en una maraña de acuerdos comerciales multilaterales, regionales y bilaterales. Más recientemente, algunos gobiernos del área han emprendido 
iniciativas políticas y económicas más amplias, las cuales van más allá de la integración económica, pues incluyen cooperación en dinero, finanzas, energía e infraestructura. Como resultado, una compleja red de regímenes integrados, superpuestos y paralelos caracteriza al Hemisferio Occidental. ¿Cómo es que la reciente proliferación y la creciente diversidad de los convenios han afectado la dinámica de la cooperación entre países latinoamericanos? Aún más importante es considerar si la densidad creciente de los regímenes económicos en la región ha operado en favor o en contra de la efectividad de los esfuerzos de colaboración. Asimismo, conviene considerar qué revela el caso de los acuerdos superpuestos regionales en América Latina para los efectos de la complejidad de regímenes en la gobernanza regional.

Para contestar estas interrogantes, parto de la bibliografía floreciente sobre complejidad de régimen internacional en relaciones internacionales y en derecho internacional. Este trabajo alumbra diversos mecanismos por los cuales la proliferación institucional y las interacciones interinstitucionales influyen en la dinámica y sustentabilidad de la cooperación interestatal. Por una parte, la complejidad del régimen internacional podría tener efectos de retroalimentación positivos que mejoren la cooperación y la efectividad de las instituciones existentes; por la otra, la superposición institucional podría promover el comportamiento de intereses propios y la competencia entre los actores y los regímenes, con que acabaría debilitándose el éxito de las iniciativas de cooperación. ${ }^{1}$ Desarrollando estas nociones, discuto evidencia empírica que sugiere la presencia y relevancia de algunos de estos mecanismos en Latinoamérica. Me concentro en tres vías por las que la proliferación de comercio internacional y acuerdos económicos ha socavado el éxito de la cooperación entre países latinoamericanos. En primer lugar, al agregar fragmentación legal y ambigüedad en las reglas, la complejidad del régimen ha exacerbado los problemas en la implementación y el cumplimiento en las iniciativas de cooperación regional de Latinoamérica. En segundo lugar,

${ }^{1}$ Karen Alter y Sophie Meunier, "The Politics of International Regime Complexity”, Perspectives on Politics, vol. 7, núm. 1, 2009, pp. 13-24. 
a la vez que amplían las opciones estratégicas disponibles a los Estados en la región, la proliferación de acuerdos ha facilitado estrategias de intereses particulares entre instituciones, lo cual se explota típicamente y con mayor efectividad por los Estados más poderosos. Por último, la dinámica competitiva entre Estados y regímenes con visiones y objetivos divergentes quebranta la cohesión y la solidaridad regionales.

La complejidad del régimen, de esa forma, ensancha las posibilidades de oportunismo para los Estados, lo cual a su vez exacerba un problema que por décadas ha dificultado los esfuerzos de cooperación regional en América Latina. En gran medida, de hecho, la proliferación de acuerdos que se superponen ha sido por sí misma una consecuencia de la falta de compromiso y de las divergencias en aumento en los intereses e ideologías entre los países de la región. El argumento aquí es que la proliferación de acuerdos que se superponen refuerza estas dinámicas, lo que conduce a su fragmentación ulterior. En este sentido, la creciente complejidad de régimen en América Latina puede verse como otro factor que contribuye a la erosión de la plena utilidad de las iniciativas de cooperación regional. Esto ha sido referido como el "deceso" o el "punto máximo" del regionalismo. ${ }^{2}$

Este artículo se estructura de la siguiente manera. La siguiente sección presenta el marco teórico que guía el análisis empírico. En la tercera sección, describo la evolución de las tentativas de cooperación en América Latina desde principios de la década de 1990. Muestro que el panorama actual de la cooperación económica regional en el Hemisferio Occidental se caracteriza por la creciente complejidad y superposición de diferentes tipos de comercio y de acuerdos económicos. En la cuarta sección, discuto las consecuencias de la superposición de comercio y compromisos económicos,

${ }^{2}$ Véase, por ejemplo, Nicola Phillips y G. Prieto, "The Demise of the New Regionalism: Reframing the Study of Contemporary Regional Integration in Latin America”, en Alex Warleigh-Lack, N. Robinson y Ben Rosamond (eds.), New Regionalism and the European Union: Dialogues, Comparisons and New Research Directions, Londres/Nueva York, Routledge-ECPR, 2011; y Andres Malamud y Gian Luca Gardini, "Has Regionalism Peaked? The Latin American Quagmire and Its Lessons", International Spectator: Italian Journal of International Affairs, 47, 1, 2012, pp. 116-133. 
en competencia y complementarios, en América Latina. La sección final consiste en una breve conclusión.

\section{MARCo TEÓRICO: INTERACGIONES INSTITUCIONALES Y COMPLEJIDAD DEL RÉGIMEN}

En las últimas dos décadas, los especialistas en relaciones internacionales comenzaron a poner atención a la densidad y superposición crecientes entre los convenios institucionales en el sistema internacional. Esta discusión buscaba superar trabajos previos que consideraban los regímenes internacionales como "acuerdos autónomos e independientes", y que hacían hincapié en los nexos entre los acuerdos institucionales específicos en el sistema internacional. ${ }^{3}$ Es de suma importancia que los académicos comenzaron a reconocer que la efectividad de las instituciones internacionales se encuentra condicionada crucialmente por las formas en que interactúan con otras instituciones y acuerdos. ${ }^{4}$

Los trabajos anteriores sobre interacción institucional ofrecían maneras alternativas de clasificar los diferentes tipos de vínculos institucionales. La obra de Aggarwal, por ejemplo, arrojó luz sobre la dinámica de la complejidad del régimen internacional al señalar las diferentes formas en que nuevas instituciones pueden conciliarse con las que ya existen. ${ }^{5}$ Él distinguió entre acuerdos jerarquizados y acuerdos horizontales o paralelos. Mientras que la jerarquización incluye algún tipo de ordenación supeditada, los regímenes horizontales lidian con actividades relacionadas, pero

${ }^{3}$ Oran Young, "Institutional Linkages in International Society: Polar Perspectives”, Global Governance, vol. 2, núm. 1, 1996, pp. 1-24.

${ }^{4}$ Sebastian Oberthur y Thomas Gehring, "Institutional Interaction: Ten Years of Scholarly Development”, en Sebastian Oberthur y Olav Schram Stokke (eds.), Managing Institutional Complexity: Regime Interplay and Global Environmental Change, Cambridge, MIT Press, 2011, pp. 25-35.

${ }^{5}$ Vinod Aggarwal, Liberal Protectionism: The International Politics of Organized Textile Trade, Berkeley, University of California Press, 1985; y Vinod Aggarwal, Institutional Designs for a Complex World: Bargaining, Linkages, and Nesting, Ithaca, Cornell University Press, 1998. 
no siguen un orden jerárquico. ${ }^{6}$ Por su parte, Young distinguió cuatro tipos de vinculación institucional: instituciones incorporadas, anidadas, agrupadas y superpuestas [embedded, nested, clustered, and overlapping institutions]. La mayoría de los acuerdos institucionales sobre un tema específico tiende a estar "incorporada" a conjuntos de principios más amplios e incluyentes, y a normas que además influyen en sus particulares reglas y procedimientos de toma de decisiones. ${ }^{7}$ Algunos regímenes, por el contrario, tienden a estar "anidados" en marcos institucionales más amplios que se ocupan de la misma área temática o dominio geográfico, aunque con menos detalle. Un tipo diferente de vínculo resulta del "agrupamiento" o reunión de diversos acuerdos distintos en paquetes institucionales, sin lógica funcional o temática específica. Finalmente, los regímenes "superpuestos" son aquellos en que hay una intersección entre el ámbito funcional de acuerdos institucionales separados. 8

A partir de estas obras, otros han examinado las consecuencias de las interacciones institucionales, atendiendo específicamente a si las mismas conducen a conflictos o a dinámicas sinérgicas. Opuesto a las expectativas preliminares de que la proliferación de instituciones llevaría a un conflicto entre ellas, la investigación empírica mostró que las interacciones pueden resultar en ajustes y sinergias mutuamente benéficos. ${ }^{9}$ Los estudiosos también comenzaron a mirar más de cerca a los mecanismos causales y a los senderos específicos por los que las instituciones se influyen entre sí. Raustiala y Victor hacen una importante contribución en este sentido. ${ }^{10}$ Primero, introducen el concepto de "complejo de regímenes", que definen como "una variedad de instituciones no jerárquicas y que parcialmente se superponen las cuales gobiernan un área temática

${ }^{6}$ Aggarwal, Liberal Protectionism.

${ }^{7}$ Young, "Institutional Linkages in International Society".

${ }^{8}$ Loc. cit.

${ }^{9}$ Amandine Orsini, Jean-Frédéric Morin y Oran Young, "Regime Complexes: A Buzz, a Boom, or a Boost for Global Governance?”, Global Governance, vol. 19, núm. 1, 2013.

${ }^{10}$ Kal Raustiala y David G. Victor, "The Regime Complex for Plant Genetic Resources”, International Organization, vol. 58, núm. 2, abril de 2004, pp. 277-309. 
particular". Una característica central de este "tipo conglomerado de régimen" es el hecho de que mientras que hay superposición entre los principios y reglas de diferentes acuerdos institucionales, no hay jerarquía para resolver las inconsistencias y conflictos que podrían surgir entre ellos. En segundo lugar, exploran las consecuencias de esta falta de un claro orden jerárquico, argumentando que ésta permite a los actores estatales y no estatales entablar negociaciones en diferentes campos, seleccionando allí donde sus intereses mejor se cumplan. Enfocándose en el control de recursos fitogenéticos, demuestran también que la complejidad del régimen tiende a resultar en la dependencia y en inconsistencias legales.

En un esfuerzo para fortalecer la base teórica y el enfoque empírico de este trabajo, un proyecto reciente conducido por Alter y Meunier se concentra en las consecuencias de la complejidad del régimen internacional sobre las políticas de la cooperación internacional en distintas áreas temáticas, incluido el comercio, la seguridad, derechos humanos, migración y propiedad intelectual. ${ }^{11} \mathrm{La}$ complejidad del régimen internacional (CRI) "se refiere a la presencia de regímenes anidados, parcialmente superpuestos y paralelos, los cuales no están organizados jerárquicamente". ${ }^{12}$ Identifican varios caminos por los que la complejidad del régimen internacional conforma las estrategias de toma de decisiones y las elecciones de actores estatales y no estatales, de modo que influye en la política de cooperación internacional. Primero, la complejidad del régimen internacional contribuye a la fragmentación de la ley internacional y a la ambigüedad de las reglas, lo que permite a los Estados implementar acuerdos basados en la interpretación selectiva, con que se cambian las políticas hacia la fase de implementación de la cooperación. En segundo lugar, los regímenes que se superponen facilitan las estrategias políticas interinstitucionales, tales como la selección de foros convenientes, cambio de régimen e inconsistencia estratégica, lo que puede permitir a los actores influenciar el contexto político y la naturaleza misma del régimen. Además, la complejidad del régimen puede ahondar en la dependencia de los actores en

${ }^{11}$ Alter y Meunier, op. cit.

12 Ibid., p. 13. 
la heurística, lo que incrementa la relevancia de los expertos que contribuyen a la dinámica de grupos pequeños. Por último, podría haber repercusiones y efectos retroactivos entre las instituciones que se superponen que facilitasen o entorpecieran la cooperación. En particular, los académicos han destacado la dinámica competitiva que tiende a aparecer entre instituciones con mandatos superpuestos y membrecías. ${ }^{13}$ Mientras que las presiones competitivas pueden promover la innovación y la experimentación productiva, la competencia por recursos, miembros y funciones podría también crear ineficiencias y socavar la efectividad de los esfuerzos conjuntos para atender un problema internacional.

Drezner reitera además los riesgos asociados con la complejidad de régimen, señalando las formas en que la proliferación institucional puede exacerbar, más que mitigar, las asimetrías del poder interestatal. ${ }^{14} \mathrm{Al}$ incrementar el número de "focos de atención" disponibles en torno a los cuales convergen las expectativas de los actores, con que se introducen mandatos potencialmente conflictivos y se incrementan los costos de cumplimiento, la complejidad del régimen privilegia las potencias poderosas a expensas de los Estados más débiles y de los actores no estatales. Los Estados poderosos tienen las capacidades técnicas y materiales de tomar ventaja de la flexibilidad provista por la existencia de múltiples opciones institucionales. No sólo están mejor preparados que sus contrapartes más débiles para recurrir a estrategias interinstitucionales como la búsqueda de escenarios favorables y el cambio de regímenes; además, tienen la experiencia legal y técnica para confrontar la fragmentación legal y las inconsistencias asociadas con la proliferación institucional.

Recientemente, un grupo de académicos ha intentado determinar con mayor claridad las diversas propiedades de los complejos de regímenes -ya sean centralizados, fragmentados o densos-, así como esclarecer cómo estos aspectos influencian el impacto de estos

13 Thomas Ghering y Benjamin Faude, "The Dynamics of Regime Complexes: Microfoundations y Systemic Effects”, Global Governance, vol. 19, núm. 1, 2013, pp. 119-130.

${ }^{14}$ Daniel Drezner, "The Power and Peril of International Regime Complexity”, Perspectives on Politics, vol. 7, núm. 1, 2009, pp. 65-70. 
sistemas en los resultados de la gobernanza global. ${ }^{15} \mathrm{Al}$ proponer una definición alternativa de complejo de regímenes -"una red de tres o más regímenes internacionales que se relacionan por un tema común, que muestran membrecías superpuestas y que generan interacciones sustantivas, normativas u operativas, que se reconocen como potencialmente problemáticas..."-, los autores no se enfocan en las consecuencias de estos complejos sobre el comportamiento y las alternativas de los actores estatales y no estatales, como Alter y Meunier habían hecho inicialmente. ${ }^{16}$ En cambio, se concentran en los efectos sistémicos más amplios de los complejos de regímenes sobre los prospectos para la cooperación y la gobernanza global efectiva, mostrando que los sistemas fragmentados tienden a ser menos exitosos para gestionar y resolver problemas transnacionales que sus contrapartes más centralizadas. ${ }^{17}$

La creciente bibliografía sobre la complejidad del régimen ofrece una serie de apreciaciones iluminadoras que pueden aplicarse al estudio de la densidad institucional progresiva y de la superposición en América Latina. En la siguiente sección me sirvo de estas nociones para examinar empíricamente, en mayor y en menor escala, las consecuencias de la creciente complejidad institucional; es decir, no sólo cómo se ha conformado el comportamiento de los Estados y de los actores dentro de los regímenes, sino también sus mayores consecuencias para la estabilidad y la efectividad de la gobernanza regional. Presento evidencia empírica que sugiere que la complejidad del régimen internacional ha contribuido a socavar la efectividad de la cooperación regional en América Latina por medio de al menos tres mecanismos:

1. La complejidad del régimen internacional ha resultado en fragmentación legal y vaguedad regulatoria, lo cual ha incrementado los costes técnicos y burocráticos del cumplimiento y la

15 Orsini et al., "Regime Complexes". Véase también Jean-Frédéric Morin y Amandine Orsini, "Regime Complexity and Policy Coherence: Introducing a CoAdjustments Model”, Global Governance, vol. 19, núm. 1, 2013, pp. 41-51.

${ }^{16}$ Orsini et al., "Regime Complexes".

${ }^{17}$ Véase, por ejemplo, Matias Margulis, "The Regime Complex for Food Security: Implications for the Global Hunger Challenge”, Global Governance, vol. 19, núm. 1, 2013, pp. 63-67. 
implementación. Además, ha permitido a los Estados comportarse de forma oportunista al implementar reglas selectivamente y "encubrir" el no cumplimiento y los déficits de la implementación. La complejidad del régimen internacional puede exacerbar así los problemas del cumplimiento en los acuerdos regionales de América Latina.

2. La complejidad del régimen internacional ha facilitado las estrategias políticas interinstitucionales, como el cambio de régimen, la búsqueda de foros convenientes y la inconsistencia estratégica, que permiten a los Estados remodelar las políticas de cooperación. Dado que los actores poderosos tienden a estar mejor ubicados para explotar estas oportunidades, la complejidad del régimen puede reforzar las asimetrías de poder en la cooperación de los regímenes del Hemisferio Occidental.

3. La coexistencia de regímenes paralelos y superpuestos con lógicas económicas y políticas competitivas debilita la coherencia y la cohesión regionales, conque se agrava la fragmentación y los intereses divergentes.

\section{El PANORAMA CAMBIANTE DEL COMERCiO Y LA COOPERACIÓN ECONÓMica en AmÉrica Latina}

El final de la Guerra Fría animó un nuevo impulso de regionalismo en América Latina, a la vez que en otras regiones del mundo. A inicios y mediados de la década de 1990, los países latinoamericanos firmaron una serie de acuerdos preferenciales, o de "complementación económica" (ACE), en el marco de la Asociación Latinoamericana de Integración (ALADI). Se crearon también cuatro uniones aduaneras en este periodo: el Mercado Común del Sur (Mercosur), la Comunidad Andina (CAN), el Sistema de la Integración Centroamericana (SICA) y la Comunidad del Caribe (Caricom). El Tratado de Libre Comercio de América del Norte, que reunió a México con Canadá y Estados Unidos, se estableció a su vez en 1994. Paralelo a estas iniciativas subregionales, Estados Unidos lanzó negociaciones para el establecimiento de un Área de Libre Comercio de las Américas (ALCA), con el objetivo de alcanzar liberalización económica para 2005. 
El resurgimiento de la cooperación regional en los años noventa fue bien acogido en la elaboración de políticas y en los círculos académicos. ${ }^{18}$ En particular, los analistas destacaron las diferencias entre este nuevo impulso de regionalismo "abierto" y los proyectos de integración regional orientados hacia adentro de los años cincuenta y sesenta. ${ }^{19}$ La estrategia de liberalización de comercio regional, buscada a la par de la apertura unilateral y mulilateral, condujo a una expansión sin precedentes de los niveles de comercio intrarregional. Como fuera, hacia finales de los noventa, los bloques de comercio latinoamericanos parecían perder fuerza. El deterioro de las condiciones internas y externas a finales de la década irrumpió severamente las relaciones comerciales en la región. A principios de la década de 2000 se atestiguó el estancamiento, gradual mas progresivo, en el proceso de negociaciones comerciales hemisféricas, que acabaron por suspenderse en 2005.

El colapso del ALCA, en combinación con el punto muerto en las negociaciones del comercio internacional y la desilusión en aumento por las reformas neoliberales a lo largo de América Latina, afectó significativamente los patrones de la cooperación económica regional en el Hemisferio Occidental en la década de 2000. Desde entonces, dos nuevos modelos de comercio y de acuerdos económicos en la región se han materializado: 1) la proliferación de acuerdos preferenciales de comercio con socios intrarregionales y extrarregionales; y 2) la aparición de proyectos más amplios de regionalismo "post-neoliberal" que buscan superar la cooperación comercial. Estas dos estrategias de regionalismo han evolucionado a la par con los acuerdos de integración más profundos creados en la década de 1990, lo que condujo a un mosaico cada vez más complejo de instituciones que se superponen.

Proliferación de acuerdos preferenciales de comercio bilaterales e interregionales. Algunos países latinoamericanos -notablemente Chile y México- comenzaron a depender de acuerdos bilaterales de

18 Inter-American Development Bank (IDB), Beyond Borders: The New Regionalism in Latin America, Washington, D. C., Inter-American Development Bank, 2002.

${ }^{19}$ Robert Devlin y Antoni Estevadeordal, "What's New about the New Regionalism in the Americas?", en Victor Bulmer-Thomas (ed.), The Political Economy of Regionalism in Latin, Londres, Institute of Latin American Studies, 2001. 
comercio con socios intrarregionales y extrarregionales en la segunda mitad de los años noventa. De cualquier forma, el número de acuerdos preferenciales de comercio bilaterales firmados por países latinoamericanos creció dramáticamente después de 2003. La frustración por el avance lento y ulterior ruptura de las negociaciones del ALcA también llevó a Estados Unidos a negociar acuerdos separados con países viables dispuestos a emprender reformas regulatorias a cambio de acceso preferencial al mercado estadounidense. ${ }^{20}$ En efecto, los acuerdos de libre comercio bilateral pronto se convirtieron en la piedra angular de la estrategia estadounidense de "liberalización competitiva". ${ }^{21}$ Entre 2004 y 2007, Estados Unidos cerró acuerdos con Chile, América Central y República Dominicana, Colombia, Ecuador, Perú y los países del Caribe. Como el TLCAN, estos acuerdos asimétricos son "omc-plus"; esto significa que su alcance sobrepasa el comercio de bienes y servicios, pues incluye otros asuntos como la regulación de la inversión y los derechos de propiedad intelectual. ${ }^{22}$

$\mathrm{Al}$ aumento de acuerdos bilaterales intrarregionales abona y complementa una tendencia al "transcontinentalismo". ${ }^{23}$ México y Chile fueron líderes en esta materia, al firmar acuerdos con la Unión Europea en 2001 y 2003 respectivamente. Desde entonces, Chile ha consignado acuerdos con Corea (2004), China (2006), Nueva Zelanda, Singapur, Brunéi (2006), Japón (2007) y Australia (2008). México, a su vez, ha completado negociaciones con Israel (2000) y Japón (2004). Perú también se mantiene activo en este frente, al establecer recientemente acuerdos de comercio regional

${ }^{20}$ Kenneth Shadlen, "Globalization, Power, and Integration: The Political Economy of Regional and Bilateral Trade Agreements in the Americas", Journal of Development Studies, vol. 44, núm. 1, 2008, pp. 1-20; Cintia Quiliconi y Carol Wise, "The US as a Bilateral Player: The Impetus for Asymmetric Free Trade Agreements", en Mireya Solís, Barbara Stallings y Saori Katada (eds.), Competitive Regionalism: FTA Diffusion in the Pacific Rim, Nueva York, Palgrave, 2009, pp. 97-117.

${ }^{21}$ Solís, Stallings y Katada (eds.), op. cit.

22 Diego Sánchez-Ancochea y Kenneth Shadlen (eds.), The Political Economy of Hemispheric Integration, Nueva York, Palgrave, 2008.

${ }^{23}$ Antoni Estevadeordal y Kati Suominen, Bridging Regional Trade Agreements in the Americas, Washington, D. C., Inter-American Development Bank, 2009. 
con Tailandia (2005), China (2009) y Singapur (2008). Las negociaciones entre los bloques de comercio regional crecieron igualmente. En 2008, la Unión Europea y la Comunidad Andina firmaron un tratado de libre comercio. El Mercosur, la Comunidad Andina y el Sistema de Integración Centroamericana se encuentran también en proceso de negociar acuerdos de asociación con el bloque europeo. El Mercosur firmó asimismo un acuerdo preferencial con la Unión Aduanera de África Austral (sAcu por sus siglas en inglés).

En los últimos años, Estados Unidos pasó también a una estrategia de transcontinentalismo al unirse al Acuerdo Económico Trans-Pacífico de Asociación Económica (TPP por sus siglas en inglés: Trans Pacific Partnership Agreement) en 2008. Inicialmente, un acuerdo de comercio entre Chile, Singapur, Nueva Zelanda y Brunéi, el тPр incluye ahora a Australia, Perú, Vietnam y Malasia. Además, en junio de 2012 cuatro países latinoamericanos en la cuenca del Pacífico, México, Colombia, Perú y Chile, firmaron un nuevo tratado de libre comercio, supuestamente destinado a promover las oportunidades comerciales con la región de Asia-Pacífico. ${ }^{24}$ Aparte de dedicarse a liberalizar todas las barreras arancelarias sobre bienes y servicios para 2020, los cuatro países de la llamada Alianza del Pacífico acordaron consolidar sus bolsas de valores en un Mercado Integrado Latinoamericano (MILA).

Regionalismos "postneoliberales". Con la llegada de gobiernos de izquierda en varios países en la región a comienzos de la década de 2000, se reemplazó el modelo neoliberal de desarrollo previo con una estrategia económica más intervencionista que se ocupaba con especial atención de objetivos sociales y de distribución. La erosión de la "convergencia liberal”, dominante en la década de 1990, dio espacio para la adopción de estrategias de inserción internacional y regional heterogéneas y a veces divergentes, tales como la Unasur y la ALBA. ${ }^{25}$ En efecto, estos proyectos "postliberales" eran en parte una respuesta al fracaso percibido en

${ }^{24}$ Véase, por ejemplo, "La Alianza del Pacífico echa a andar en Chile", El País, 6 de junio de 2012.

${ }^{25}$ Pedro Da Motta Veiga y Sandra Rios, $O$ regionalismo pós-liberal na América do Sul: origens, iniciativas e dilemas, CEPAL, 2007, p. 17. (Serie Comercio Internacional, núm. 82) 
el modelo previo de regionalismo "abierto". ${ }^{26}$ Ambas iniciativas rechazan el enfoque estrecho sobre la interdependencia comercial de las áreas de libre comercio y uniones aduaneras de los años noventa, y buscan ensanchar el alcance de la colaboración hacia otras áreas económicas y no económicas, donde se incluye energía, seguridad y temas culturales. Un programa central en la Unasur ha sido la Iniciativa para la Integración de la Infraestructura Regional Suramericana (IIRSA), con que se promueve el desarrollo de la infraestructura de transporte, energía y telecomunicaciones, con el fin de facilitar la integración física entre países sudamericanos.

Ambos programas regionales han sido también han puesto especial atención en la cooperación en asuntos financieros y monetarios. En 2007, siete de los doce miembros de la Unasur acordaron la creación del Banco del Sur, con la meta concreta de reafirmar su independencia política y financiera de las instituciones financieras con base en Washington, particularmente el Fondo Monetario Internacional (FMI) y el Banco Mundial. ${ }^{27}$ En abril de 2009, los miembros de la ALBA firmaron el acuerdo para la creación de un Sistema Unitario de Compensación Regional de Pagos (sucre), con que se establecieron las bases para una moneda regional común. ${ }^{28}$ El sucre se concibió como un medio de intercambio para usarse en todas las transacciones comerciales entre miembros de la ALBA y con el objetivo final de reducir la dependencia en los dólares estadounidenses en intercambios regionales, conque se fortalecería la soberanía de los países latinoamericanos.

${ }^{26}$ La ALBA se lanzó oficialmente en 2004 con la firma de un acuerdo entre Venezuela y Cuba. Desde entonces, Bolivia, Nicaragua, Dominica, Honduras, Ecuador, San Vicente y las Granadinas y Antigua y Barbuda se han unido al acuerdo. La Unasur se estableció formalmente en 2008 como institución intergubernamental que se unía al Mercosur y a la Comunidad Andina con Surinam y Guyana. Su predecesor, la Comunidad de Naciones Suramericanas, se creó en 2004.

${ }^{27}$ Antulio Rosales, "El Banco del Sur: (des)acuerdos sobre una arquitectura financiera alternativa”, documento inédito, Universidad Central de Venezuela, 2010, http://www.rls.org.br/informes/Banco_del_Sur_y_Sucre-_Antulio_Rosales_.pdf

28 Sistema Económico Latinoamericano y del Caribe (SELA), "Experiencias de cooperación monetaria y financiera en América Latina y el Caribe: balance crítico y propuestas de acción de alcance regional”, SP/Di N. 10-09, 2009. 


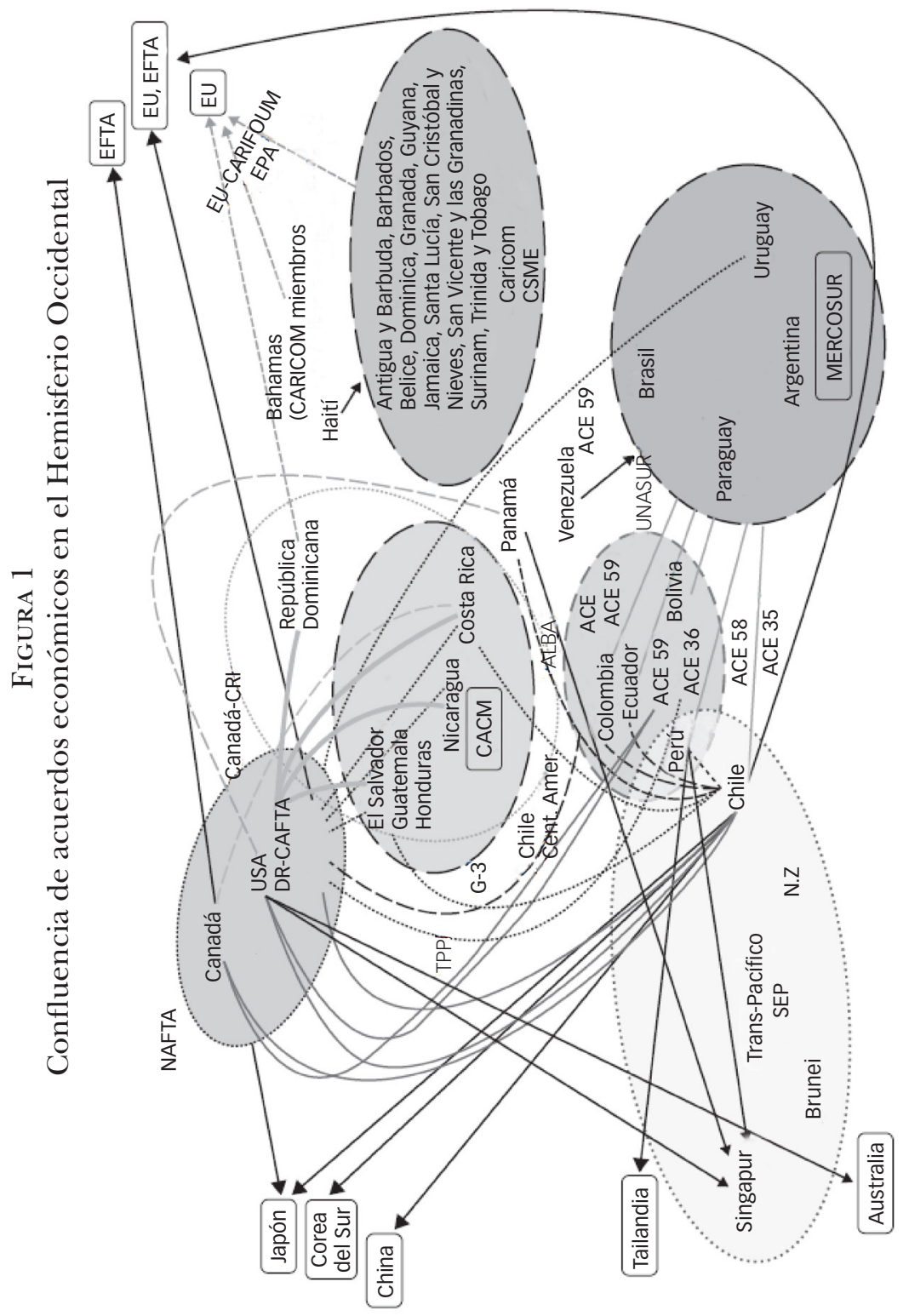


En suma, el panorama actual de comercio y cooperación económica en el Hemisferio Occidental se caracteriza por la superposición creciente de convenios económicos regionales de diversidad considerable en su alcance y profundidad; entre ellos están las uniones aduaneras, las áreas bilaterales de libre comercio y las iniciativas políticas y económicas (véase la figura 1). ¿Cuáles son las consecuencias de estas crecientes complejidad y densidad de régimen? ¿Cómo la coexistencia y la interacción de diversos acuerdos han afectado las estrategias políticas y las decisiones de los actores estatales y no estatales de la región? La siguiente sección explorará empíricamente estas cuestiones.

\section{Consecuencias de La COMPlejidad del RÉGimen \\ E INTERACGIONES INTERINSTITUCIONALES}

\section{Complejidad del régimen y problemas de implementación}

Los países latinoamericanos tienen un historial de implementación pobre de las iniciativas de integración regional. Domínguez, por ejemplo, ha argumentado que "el descuido en la implementación" ha sido una característica constante de la cooperación comercial en Latinoamérica. ${ }^{29}$ La generalizada implementación negligente queda por lo común impune y "se acepta, incluso cuando su existencia entorpece los procedimientos u organizaciones que los Estados participantes buscaban crear". ${ }^{30}$ Como destaca un reporte reciente de la cEPAL sobre el estado del regionalismo en América Latina y el Caribe, pese al notable progreso los principales bloques comerciales en la región siguen afectados por la persistencia de huecos en los aranceles externos comunes y el fracaso de los miembros para

${ }^{29}$ Jorge Domínguez, "International Cooperation in Latin America: The Design of Regional Institutions by Slow Accretion”, en Amitav Acharya y Alastair Johnston (eds.), Crafting Cooperation: Regional Interdependence in Comparative Perspective, Cambridge, Cambridge University Press, 2007.

${ }^{30}$ Domínguez, "International Cooperation in Latin America”, p. 95. 
completar los convenios de las uniones aduaneras. ${ }^{31}$ Le reciente abundancia de acuerdos superpuestos ha exacerbado este cumplimiento y el problema de la implementación de varias maneras.

En primer lugar, mientras que la expansión de acuerdos preferenciales ha llevado a una significativa liberalización comercial entre los países de la región, el aumento en reglamentos que se superponen ha incrementado los costos de transacción tanto para los actores como para los gobiernos. ${ }^{32} \mathrm{El}$ hecho de que muchos de estos acuerdos difieran en sus disciplinas de mercado, incluidos los calendarios de liberalización comercial, normas de inversión, normas de origen y medidas de salvaguarda, complica al final el panorama para los negociadores, inversionistas y otros actores del sector privado. En efecto, los costes administrativos y técnicos de cumplimiento y aplicación aumentaron drásticamente con la firma de acuerdos asimétricos que van más allá de los asuntos comerciales tradicionales. El Tratado de Libre Comercio entre Estados Unidos, Centroamérica y República Dominicana (DR-CAFTA por sus siglas en inglés) se ha contemplado como un "microcosmos que ilustra muchas de las mismas preocupaciones y cuestiones planteadas en América Latina respecto a la coexistencia, superposición y convergencia de los acuerdos". ${ }^{33}$

En efecto, dicho tratado es uno de los acuerdos recientes más complejos, que conjunta tres tratados de libre comercio preexistentes, a saber: el acuerdo entre los cinco países de Centroamérica (SICA), el acuerdo entre estos cinco países y República Dominicana y los acuerdos de libre comercio entre Estados Unidos y cada uno de estos seis países. Pese a las semejanzas entre los tres convenios, diferencias diversas y superposiciones presentan fragmentación y constituyen un "problema real" para los negociadores y las autoridades. ${ }^{34}$ Un aspecto particularmente confuso y potencialmente

${ }^{31}$ Mikio Kuwayama, José Durán Lima y Verónica Silva, Bilateralism and Regionalism: Reestablishing the Primacy of Multilateralism: A Latin American and Caribbean Perspective, Santiago de Chile, United Nations Eclac Publications, 2005.

32 Estevadeordal y Suominen, Bridging Regional Trade Agreements.

33 Jaime Granados y Rafael Cornejo, "Convergence in the Americas: Some Lessons from the DR-CAFTA Process”, The World Economy, vol. 29, núm. 7, 2006, p. 881.

${ }^{34}$ Granados y Cornejo, "Convergence in the Americas". 
problemático es la superposición entre el nuevo régimen de origen multilateral y los regímenes preexistentes en los otros acuerdos. Aunque la coexistencia de regímenes se quería para mitigar los efectos de un cambio de reglas repentino, en la práctica ha significado que para algunos productos dos conjuntos distintos de normas de origen son aplicables, lo que permite a los actores privados elegir así normas predilectas.

Pero, aparte de incrementar los costes técnicos de aplicación, la complejidad del régimen internacional también influye en la política de implementación. En primer lugar, la negociación y la implementación de acuerdos superpuestos requieren no sólo amplia capacidad técnica, sino coordinación en diferentes campos. Ha incrementado el número de cumbres y encuentros a los que deben asistir funcionarios públicos, lo que agrega presión a los presupuestos nacionales. ${ }^{35}$ Más aún, al alcance más amplio de muchos de estos convenios también requiere el compromiso de ministerios diversos y agencias gubernamentales y su coordinación con otros actores económicos, incluidos grupos de negocios y alianzas. ${ }^{36}$

En segundo lugar, en un complejo de regímenes, la existencia de normas y jurisdicciones superpuestas merma la claridad de las obligaciones legales y representa ambigüedad de normas. Los Estados pueden sacar ventaja de la fragmentación y la ambigüedad, al seleccionar su norma preferida, o interpretando e ignorando aquellas que no reflejan ni benefician sus intereses nacionales. En términos de Helfer, la complejidad pone a los Estados a "resguardo" para implementar sus interpretaciones predilectas de normas ambiguas. ${ }^{37}$ La proliferación de normas ambivalentes y potencialmente contradictorias en instituciones anidadas, superpuestas y paralelas, da más espacio a los Estados para enfrentar las críticas a un comportamiento que transgreda sus obligaciones legales.

35 Malamud y Gardini, "Has Regionalism Peaked?”.

${ }^{36}$ Pablo Heidrich y Diana Tussie, "Regional Trade Agreements and the wTo: The Gyrating Gears of Interdependence”, en Debra Steger (ed.), Redesigning the World Trade Organization for the $21^{\text {st }}$ Century, Ottawa, Wilfrid Laurier University Press, 2009.

${ }^{37}$ Laurence Helfer, "Regime Shifting in the International Intellectual Property System”, Perspectives on Politics, vol. 7, núm. 1, 2009, pp. 39-44. 
La proliferación institucional ha ayudado sin duda a los países latinoamericanos a "esconder" la amplia brecha de implementación que caracteriza a la mayor parte de los acuerdos económicos y comerciales de la región. Además de las continuas imperfecciones en los aranceles externos comunes, los ambiciosos proyectos regionales establecidos en los años noventa incluyen varios tipos de excepciones a la liberalización intrarregional para países y sectores específicos. En los bloques comerciales sudamericanos, por ejemplo, países más pequeños, como Perú (en la Comunidad Andina), Paraguay y Uruguay (en Mercosur) han sostenido procesos de liberalización más pausados. Añádase que muchos de los acuerdos concertados en las últimas dos décadas ofrecen trato especial a varios de los llamados "sectores sensibles", que incluyen productos agropecuarios, textiles y calzado. ${ }^{38}$ En vez de avanzar en la eliminación de estas exenciones e imperfecciones, los países latinoamericanos tienden a desviar su atención de estos asuntos pendientes con la firma de nuevos acuerdos, a veces más ambiguos. La creación de la ALBa y la Unasur cuando proyectos de larga trayectoria como el Mercosur y la Comunidad Andina de Naciones no se han implementado del todo ilustra esta tendencia. ${ }^{39}$

Existe también evidencia de que la creciente fragmentación legal y la superposición entre acuerdos permite a los países participar en implementaciones selectivas y estratégicas para promover sus intereses. Una disputa reciente entre Costa Rica y El Salvador ilustra este tipo de conducta. En septiembre de 2013, Costa Rica acusó a El Salvador de violar las reglas del DR-CAFTA luego de que El Salvador supuestamente se rehusara a implementar las disposiciones de reducción de aranceles contenidas en este acuerdo sobre las importaciones de neumáticos y jugos de Costa Rica. ${ }^{40}$ Costa

${ }^{38}$ Estevadeordal y Suominen, Bridging Regional Trade Agreements.

39 Por ejemplo, en 2012 los países del Mercosur acordaron una nueva lista excepciones. Véase "Mercosur habilitó nueva lista de excepciones", La Nacion, 1 de julio de 2012.

${ }^{40}$ Véase, por ejemplo, "Costa Rica Accuses El Salvador of Violating FTA", CentralAmericaData.com, 24 de septiembre de 2013. Disponible en http://cen tralamericadata.com/en/article/home/Costa_Rica_acusa_El_Salvador_por_in cumplir_TLC 
Rica a su vez solicitó el establecimiento de mecanismos de concertación, aduciendo que "las autoridades comerciales salvadoreñas han interpretado que el trato preferencial de aranceles del DR-CAFTA sólo aplica a importaciones de Estados Unidos y no al resto de los signatarios del convenio". ${ }^{41}$

Otro ejemplo de interpretación y aplicación selectivas puede observarse en el intento de Argentina en 1999 de explotar la superposición entre reglas en el Mercosur y la ALADi para imponer medidas de salvaguarda sobre importaciones brasileñas. A pesar de la presión de sus países más pequeños, Brasil había resistido consistentemente la inclusión de una cláusula de salvaguarda en el Mercosur. La Resolución 70 de la ALADI, en contraste, autorizó el uso de medidas de salvaguarda en el comercio entre socios cuando la "cantidad o las condiciones de las importaciones de uno o varios productos de la región causen, o amenacen con causar, daños graves a productores nacionales o a productos similares". ${ }^{42}$ En julio de 1999 , y en respuesta a fuertes presiones internas que siguieron a la devaluación de la moneda brasileña, el gobierno argentino aprobó una resolución que regulaba la aplicación de la Resolución 70 de la ALADi en el Mercosur. De acuerdo con funcionarios argentinos, la acción estaba legal y técnicamente justificada porque cerraba la brecha institucional en la legislación del Mercosur. ${ }^{43}$

\section{Estrategias políticas interinstitucionales}

De acuerdo con la bibliografía sobre complejidad de régimen internacional, la existencia de varias instituciones diferentes con au-

${ }^{41}$ Véase: "El Salvador Calls For Regional Support in Tariff Conflict with Costa Rica”, CentralAmericanData.com, 30 de enero de 2014. Disponible en http:// centralamericadata.com/en/article/home/El_Salvador_pide_apoyo_regional_ en_conflicto_arancelario_con_Costa_Rica

42 Resolución ALADi 70/87.

${ }^{43}$ Félix Peña, "Ni tempo de funerales ni tudo bem", Archivos del Presente, 5, 17, 1999, pp. 35-48. Véase también "Itamarati teme pelo Mercosul”, Jornal do Brasil, 26 de julio de 1999; y "Mercosur: Se logró superar la peor crisis", La Nación, 30 de julio de 1999 . 
toridad sobre una cuestión permite a los Estados participar en "tableros políticos", haciendo jugadas estratégicas en un campo que podría tener efectos específicos en otras instituciones. Los estudiosos del comercio internacional han puesto especial atención en la práctica de buscar el foro más favorable, o en elegir el lugar donde los Estados creen que tienen mejores probabilidades de obtener un resultado favorable. ${ }^{44}$ La superposición de los acuerdos de comercio en Latinoamérica ofrece múltiples oportunidades para este tipo de estrategia interinstitucional, particularmente en la resolución de controversias. Todos los acuerdos de integración subregional firmados en la década de 1990, al igual que los acuerdos de comercio preferenciales negociados en la última década, contienen mecanismos formales de solución de controversias con distintas disposiciones y niveles variados de legalismo. ${ }^{45}$ Existen superposiciones de jurisdicción significativas entre estos sistemas de solución de controversias regionales y bilaterales, ${ }^{46}$ lo que permite a los gobiernos elegirlos estratégicamente de manera que se protejan sus intereses nacionales. Además, como miembros de la Organización Mundial de Comercio, pueden recurrir a procedimientos de solución de controversias para decidir disputas regionales.

Varios ejemplos del Hemisferio Occidental ilustran las formas como los gobiernos de América Latina han tomado ventaja de los conflictos legales y jurisdiccionales así como interpretaciones contradictorias causadas por sistemas de solución de controversias que se superponen. La controversia por las gaseosas entre México

${ }^{44}$ Véase, por ejemplo, Marc Busch, "Overlapping Institutions, Forum Shopping and Dispute Settlement in International Trade”, International Organization, vol. 61, núm. 4, 2007, pp. 735-761; y Saadia Pekkanen, Mireya Solís y Saori Katada, "Trading Gains for Control: International Trade Forums and Japanese Economic Diplomacy”, International Studies Quarterly, vol. 51, núm. 4, 2007, pp. 945-970.

45 James McCall Smith, "The Politics of Dispute Settlement Design: Explaining Legalism in Regional Trade Pacts”, International Organization, vol. 54, núm. 1, 2000, pp. 137-180.

46 Superposiciones de jurisdicción alude a situaciones en las que la misma controversia podría llevarse a dos distintos mecanismos de resolución. K. Kwak y Gabrielle Marceau, "Overlaps and Conflicts of Jurisdiction Between the wTo and RTAS”, en Lorand Bartels y Federico Ortino (eds.), Regional Trade Agreements and the WTO Legal System, Oxford, Oxford University Press, 2006. 
y Estados Unidos ha recibido especial atención. Estados Unidos, evitando acordar la selección de panelistas, pudo bloquear las tentativas de México para iniciar una controversia bajo el capítulo 20 del TLCAN por cuotas de azúcar no aplicadas. ${ }^{47}$ Cuando México contraatacó gravando con $20 \%$ todos los refrescos no endulzados con azúcar mexicana, Estados Unidos presentó una queja ante el Órgano de Solución de Diferencias de la omc. México insistió en que la controversia debía resolverse bajo el TLCAN, donde ya había iniciado la disputa, y no en la omc, y solicitó al comité que declinase ejercer jurisdicción. Estados Unidos, por el contrario, prefirió el mecanismo de la omc, que se considera mantiene "una postura neutral en apoyo del libre comercio" y que decide típicamente contra la imposición de medidas antidumping. ${ }^{48}$ En efecto, el comité se decidió a favor de Estados Unidos. Este resultado, según algunos, reflejó no sólo esta preferencia sino además "la inexperiencia de México y la pericia estadounidense". ${ }^{49}$

Igualmente, luego de perder la controversia ante el Mercosur contra Argentina por las regulaciones avícolas en 1999, Brasil inició procedimientos en la omc para desafiar la misma resolución. El comité de la omc ignoró las reclamaciones de Argentina de que el reglamento regional no podía ignorarse, y falló a favor de Brasil. ${ }^{50}$ Esta disputa sobre las aves de corral ilustra además otro tipo de estrategia interinstitucional, a saber, la escalada y la represalia de un foro a otro. Otro ejemplo de controversia que escaló del nivel regional al multilateral es el conflicto entre Argentina y Chile por las bandas de precio. Primero, Argentina atrajo un caso contra el sistema de bandas de precio al sistema de solución de controversias

47 La controversia atañía a cuotas azucareras asignadas a México bajo el TLCAN, pero que Estados Unidos se rehusó a cumplir. Esto llevó a México a iniciar, primero, una controversia y, cuando ésta fue bloqueada, a tomar represalias.

48 Alice Vacek-Aranda, "Sugar Wars: Dispute Settlement Under NAFTA and the wTO as Seen Through the Lens of the HFcs Case and its Effects on US-Mexican Relations", Texas Hispanic Journal of Law and Policy, 12, 2006, pp. 121-160.

${ }^{49}$ Vacek-Aranda, "Sugar Wars".

50 Jennifer Hillman, "Conflicts between Dispute Settlement Mechanisms in Regional Trade Agreements and the wTo- What Should the wTo Do?", Cornell International Law Journal, vol. 42, núm. 2, 2009, p. 198. 
del Acuerdo Mercosur-Chile (ECA-35). Mientras que el grupo de expertos falló en favor de Argentina, Chile no cumplió con sus recomendaciones. En respuesta, Argentina inició un procedimiento contra Chile ante la omc. No mucho después, Chile llevó ante la oMC un caso contra Argentina sobre dispositivos de seguridad para duraznos en conserva. En Argentina, este lance se interpretó ampliamente como "revancha". ${ }^{51}$

La bibliografía sobre complejidad del régimen identifica otro importante tipo de estrategia política interinstitucional al que los Estados pueden recurrir en un contexto de instituciones superpuestas y paralelas. El cambio de régimen se refiere a los intentos de los Estados para movilizar negociaciones y actividades de legislación de una instancia a otra de manera que se altere el statu quo y se influya la naturaleza del régimen. ${ }^{52}$ De acuerdo con Helfer, el cambio de régimen permite a Estados poderosos o débiles generar "normas opuestas al régimen", es decir, "disposiciones vinculantes a los tratados y normas no vinculantes de ley blanda que busquen ajustar el paisaje legal". ${ }^{53}$ Existen evidencias de que los países latinoamericanos han entablado estrategias de cambio de régimen en asuntos comerciales tanto como monetarios. A principios de la década de 1990, por ejemplo, Estados Unidos promovió el regionalismo como respuesta al estancamiento de las negociaciones comerciales multilaterales. A la vez que se hacía evidente el fracaso de la alternativa de integración hemisférica después de 2003, el gobierno estadounidense cambió a una estrategia de acuerdos de comercio bilateral con países "viables" en Centroamérica y Sudamérica. Este enfoque bilateral permitió a Estados Unidos beneficiarse de su habilidad de negociación, con que obtuvo acuerdos más próximos a sus objetivos, sin hacer concesiones a cambio. ${ }^{54}$

${ }^{51}$ Valentina Delich, "Trade and Dispute Settlement in South America: Concerns and Challenges in the Way to the FTAA", Integration EJ Trade, 24, 2005, pp. 3-25.

52 Helfer, "Regime Shifting in the International Intellectual Property System"; Alter y Meunier, op. cit.

${ }^{53}$ Laurence Helfer, "Regime Shifting: The TRIPs Agreement and New Dynamics of International Intellectual Property Lawmaking”, The Yale Journal of International Law, vol. 29, núm. 1, 2004, pp. 1-83.

${ }^{54}$ Nicola Phillips, "US Power and the Politics of Economic Governance in the 
Más aún, la idea detrás de la estrategia estadounidense de "liberalización competitiva" era incrementar los incentivos para que los no miembros se unieran, aumentando el número de acuerdos preferenciales de comercio y, en algún punto, incorporarlas en una red comercial global más liberalizada.

Potencias regionales como Brasil y Venezuela también han intentado remodelar la política de cooperación en la región por medio del cambio de las negociaciones hacia foros alternativos. Brasil ha promovido activamente la construcción de un régimen político y económico más amplio en Sudamérica, con el objetivo de mejorar su posición como potencia regional. Pero acaso Venezuela ha sido más audaz en su estrategia de cambio de régimen. En efecto, Chávez buscó crear normas anti-régimen como respuesta a la ALCA por medio, primero, de reforzar su alianza con los países del Mercosur y más adelante con el lanzamiento de la ALBA. Como se discutió más arriba, la ALBA se concibió de hecho como una "alternativa" al proceso de integración hemisférica guiado por Estados Unidos. La decisión del gobierno de Chávez de salir de la Comunidad Andina (CAN) y solicitar membrecía plena en el Mercosur, debe considerarse como una jugada política con el fin de equilibrar la influencia de Estados Unidos en la región y de impulsar un modelo alternativo de economía e integración. De hecho, la actitud de Venezuela es consistente con lo que Raustiala y Victor han expresado como la creación de una "inconsistencia estratégica", que es la tentativa de los Estados de crear reglas contradictorias en un régimen paralelo con el fin de debilitar a la institución original. ${ }^{55}$

Por último, Venezuela también ha dependido de cambios en el régimen para asuntos monetarios. Cuando el Banco del Sur fue concebido originalmente, algunos miembros, sobre todo Venezuela y Ecuador, apoyaron una entidad más fuerte y autónoma que pudiese servir no sólo como banco de desarrollo, sino como prestamista de última instancia y fondo de estabilización. En contraste, Brasil se mantiene como "partidario apático del Banco", que sólo respalda

Americas”, en William C. Smith y Laura Gómez-Mera (eds.), Market, State, and Society in Contemporary Latin America, Malden, Willey-Blackwell, 2010.

${ }^{55}$ Raustiala y Victor, art. cit. 
su función como institución de desarrollo que se enfoca principalmente en financiar proyectos de infraestructura. ${ }^{56}$ Luego de varios meses de negociaciones, los gobiernos sudamericanos firmaron el Convenio Constitutivo del Banco del Sur en septiembre de 2009. Según este acuerdo, la función principal del banco es "financiar proyectos de desarrollo en sectores clave de la economía, buscando promover la competitividad, el progreso científico y tecnológico, la infraestructura, y maximizando el valor agregado de las materias primas producidas en la región”. ${ }^{57}$ La frustración por el progreso lento en el establecimiento del Banco del Sur y, en particular, por su carácter desarrollista moderado, llevó a que el gobierno venezolano lanzara una propuesta alternativa para la cooperación monetaria y financiera con la ALBA. Aparte de dar a conocer una unidad común de cuenta (el SUCRE), el acuerdo de 2009 creó el Consejo Monetario Regional y el Fondo de Reservas y Convergencia, que se han visto como elemento central en la constitución de una arquitectura financiera alternativa en la región.

La complejidad del régimen también ha presentado oportunidades para que los Estados más débiles recurran a estrategias de foros entrecruzados con el fin de mejorar su influencia ante socios más poderosos. En efecto, la proliferación de instituciones paralelas amplía las opciones estratégicas disponibles para países más pequeños, lo que les permite elegir con un menú más variado de membrecías potenciales y asociaciones estratégicas, conque se incrementa su poder de negociación. A principios de la década de 1990, el fuerte interés de Argentina de incorporarse al TLCAN o de negociar un acuerdo bilateral preferencial con Estados Unidos -y la ambivalencia estratégica que implicó respecto al Mercosursirvió para mejorar su posición negociadora ante Brasil. Uruguay y Paraguay también han intentado jugar la carta de Estados Unidos para mejorar su influencia en el Mercosur. En 2008, por ejemplo, Uruguay anunció su intención de negociar un acuerdo de comercio

${ }^{56}$ Martin Hart-Landsberg, "Learning from ALBA and the Bank of the South", Monthly Review, septiembre de 2009, p. 11, en http://www.monthlyreview.org/090 901hart-landsberg.php

57 Osvaldo Rosales, Crisis internacional y oportunidades para la cooperación regional, CEPAL, 2009, p. 7. (Serie de Comercio Internacional, núm. 93) 
preferencial con Estados Unidos. Argentina y Brasil criticaron acremente esta jugada, pero, en lo que podría verse como un intento de apaciguar a su socio más pequeño, acordaron crear un fondo de convergencia estructural para mitigar las asimetrías económicas dentro del bloque. De acuerdo con Shifter (2012), en años recientes Colombia ha buscado "reequilibrar y realinear" sus relaciones exteriores y, en particular, compensar la influencia brasileña y estadounidense reconectándose con Sudamérica. La decisión de lanzar la Alianza del Pacífico en 2011, de hecho, puede verse como otro ejemplo de cambio de régimen.

\section{Competencia, normas divergentes y cohesión regional}

De acuerdo con la bibliografía sobre complejidad del régimen internacional, ésta también provoca competencia entre instituciones y actores, lo que puede tener efectos positivos y negativos en la estabilidad de la cooperación. Comúnmente la discusión sobre acuerdos comerciales se concentra en una concepción económica de la dinámica competitiva, que asume que la decisión de un país de unirse a un acuerdo de comercio preferencial provocará preocupación sobre desviación de las inversiones extranjeras entre los no miembros. Como resultado, estos países tendrán incentivos para integrarse al acuerdo original o para crear uno nuevo, de modo que se evite una pérdida de cuota de mercado o de capital extranjero. ${ }^{58}$ Solís y coautores, de cualquier forma, entienden la competencia como un "fenómeno multidimensional que se compone de elementos económicos, políticos y legales”, por el que los países compiten con sus pares por el acceso preferencial para sus corporaciones multinacionales, para ganar poder e influencia a nivel regional, o para hacerse más influyentes en el sistema internacional. ${ }^{59}$

Las presiones competitivas han conducido en parte a la proliferación de acuerdos de comercio regionales en el Hemisferio

${ }^{58}$ Richard Baldwin, “A Domino Theory of Regionalism”, NBER Working Paper 4465, 1993.

${ }^{59}$ Solís et al., Competitive Regionalism. 
Occidental y, en particular, a la más reciente ola de acuerdos de comercio preferencial bilaterales. Al mismo tiempo, el empalme que resultó entre los regímenes lleva a competencia ulterior entre éstos, lo que abre la gama de opciones institucionales para los Estados y los actores no estatales ${ }^{60}$ La competencia entre instituciones que se superponen, como algunos han advertido, podría dificultar la consolidación de la unidad regional y la colaboración. ${ }^{61}$ Por ejemplo, la creciente tendencia de miembros individuales de los grupos comerciales a separar acuerdos con socios fuera del grupo, y a veces fuera de la región, podría verse como una contribución a la fragmentación política y a la debilitación de la solidaridad regional y la cohesión. Como Malamud y Gardini lo expresan: "La realidad es que cada vez que se forma un bloque nuevo, lo hace excluyendo a países vecinos y distinguiéndose intencionalmente de las otras organizaciones (sub) regionales". ${ }^{62}$ La membrecía no exclusiva y superpuesta exacerba las fricciones en los acuerdos regionales, "estimulando las divisiones en vez de la unidad que el regionalismo pretende buscar". ${ }^{63}$

Las consecuencias adversas que la negociación de acuerdos bilaterales con Estados Unidos tuvo en los bloques regionales más tradicionales en América Latina sirven para ilustrar esta dinámica. En ninguna parte es esto más claro, que en el caso de la Comunidad Andina. La decisión de Colombia y Perú de negociar acuerdos de libre comercio con Estados Unidos llevó a una crisis en el régimen, que condujo a la salida de Venezuela del bloque y a su subsecuente solicitud para unirse al Mercosur. La salida de Venezuela de la Comunidad Andina, a su vez, se ha considerado que contribuye a la fragmentación entre los miembros restantes del bloque. ${ }^{64}$ Los analistas también han señalado las formas en que el acuerdo de libre comercio con Estados Unidos contribuyó a debilitar la cohesión regional entre los miembros del Sistema de

60 Thomas Ghering y Benjamin Faude, "The Dynamics of Regime Complexes: Microfoundations and Systemic Effects”, Global Governance, 19, 2013.

${ }^{61}$ Solís et al., Competitive Regionalism.

${ }^{62}$ Malamud y Gardini, "Has Regionalism Peaked?”.

${ }^{63}$ Loc. cit.

${ }^{64}$ Phillips y Prieto, "The Demise of the New Regionalism". 
Integración Centroamericano. Así, de acuerdo con algunos, el trato duro de Estados Unidos durante las negociaciones llevó al colapso de las posiciones comunes de negociación y dio como resultado tratos sobre una serie de productos sensibles. En este sentido, las negociaciones con Estados Unidos contribuyeron sin duda a ahondar las divisiones en y entre los países en el bloque. ${ }^{65}$ Las negociaciones entre la Comunidad Andina y la Unión Europea también crearon tensiones entre los países andinos, mientras Bolivia y Ecuador abandonaron temporalmente las pláticas en protesta de la negativa de Colombia y Perú a considerar sus necesidades distintivas. ${ }^{66}$

La entrada de Venezuela al Mercosur, por su parte, avivó aún más la agitación y la fragmentación en el siempre agitado bloque comercial sudamericano. Venezuela pidió unirse al Mercosur en 2006, y obtuvo aprobación rápida de los gobiernos de los cuatro miembros. Aún así, la ratificación interna de esta aprobación fue mucho más lenta, especialmente en Brasil y Paraguay. Luego de largas negociaciones, el senado brasileño aceptó por fin la admisión de Venezuela al bloque en 2009. En contraste, el congreso paraguayo continuó bloqueando este último paso. Cuando en junio de 2012 el presidente paraguayo Fernando Lugo fue abruptamente impugnado y reemplazado por el vicepresidente Federico Franco, los miembros del Mercosur suspendieron a Paraguay por un año alegando una violación de la cláusula democrática del bloque. En una jugada cuestionable legalmente y muy criticada, los líderes aceptaron formalmente a Venezuela como miembro pleno. Pese a que aceptó oficialmente la decisión, supuestamente por razones políticas, el gobierno uruguayo se apuró a expresar su descontento. ${ }^{67}$ De acuerdo con el vicepresidente uruguayo Danilo Astori, esto constituía un fuerte "golpe institucional" que dejaba al Mercosur "débil" y casi "inútil". ${ }^{6}$

${ }^{65}$ Vincent McElhinny, “CAFTA: Few Benefits, Many Costs”, Americas Program, Interhemispheric Resource Center, Policy Brief, febrero de 2004.

66 Phillips y Prieto, "The Demise of New Regionalism"; y Malamud y Gardini, "Has Regionalism Peaked?".

67 "Chavez: Into Mercosur by a Side Door", Financial Times, 3 de julio de 2012.

68 Astori describe las últimas decisiones del Mercosur como "agresión y fuertes golpes institucionales”, en MercoPress.com, 3 de julio de 2012. 
La investigación sobre complejidad del régimen internacional sugiere que las interacciones interinstitucionales y la dinámica competitiva son particularmente problemáticas cuando las instituciones superpuestas se basan en normas divergentes o incompatibles. ${ }^{69}$ Como notan Orsini, Moran y Young, parte de la razón por la que el complejo de regímenes de comercio global se convirtió en un sistema coherente y "sinérgico" es que sus componentes superpuestos están "fuertemente vinculados alrededor de un principio ordenador común conocido como liberalismo incorporado" [embedded liberalism $].{ }^{70}$ No existe principio común o norma en el caso de los regímenes superpuestos en el Hemisferio Occidental. Como se mencionó más arriba, los bloques del "nuevo regionalismo" creados en los años noventa compartían un enfoque de la integración y eran complementarios para el más amplio proceso de liberalización de comercio multilateral. Los acuerdos preferenciales de comercio establecidos en la década de 2000, como la reciente Alianza del Pacífico, se basan también en este enfoque liberal del libre comercio. En contraste, la Unasur y la ALBA impulsaron un modelo alternativo de integración que buscaba promover "una visión nueva del bienestar y la equidad regionales" a nivel regional. ${ }^{71}$ La ALBA, en particular, surgió como una alternativa radical al modelo de cooperación neoliberal basado en el comercio y fomentado por Estados Unidos en los años noventa, con el fin de promover un proyecto "bienestarista transnacionalizado" de cooperación en asuntos sociales y políticos. ${ }^{72}$ Como Malamud y Gardini observan, estos proyectos en competencia ofrecen respuestas incompatibles a tres cuestiones centrales del regionalismo latinoamericano: el tema del liderazgo regional, la relación con Estados Unidos y la adecuada estrategia de desarrollo. ${ }^{73}$

${ }^{69}$ Por ejemplo, Kristin Rosendal, "Impacts of Overlapping International Regimes: The Case of Biodiversity", Global Governance, vol. 7, núm. 1, 2001, pp. 95-117; y Margulis, "The Regime Complex for Food Security".

70 Orsini et al., "Regime Complexes", p. 32.

${ }^{71}$ Hart-Landsberg, "Learning from ALBA".

72 Pia Riggirozzi, "Region, Regionness and Regionalism in Latin America: Towards a New Synthesis", Latin American Trade Network, Working Paper, 130, 2010, p. 9.

${ }^{73}$ Malamud y Gardini, "Has Regionalism Peaked?”. 
La coexistencia de los dos modelos de organización económica y política en competencia en regímenes con membrecías superpuestas dificulta la búsqueda de terreno común y mueve preocupaciones sobre los prospectos de cohesión y colaboración a lo largo y ancho de la región. La fundación de la Alianza del Pacífico, por ejemplo, ha topado con preocupaciones en aumento sobre la aparición de una "división continental" ${ }^{4}$ o un nuevo eje de separación, que divide a "una América Latina del Pacífico de una América Latina del Atlántico". ${ }^{75}$ En efecto, según algunos, la ausencia de una serie compartida de principios normativos e ideacionales en proyectos subregionales latinoamericanos provoca confusión sobre la agenda política y económica central del regionalismo, lo que al final contribuye a su desaparición. ${ }^{76}$

Las dificultades para la coordinación regional se hicieron evidentes en el contexto de la reciente crisis financiera internacional. Los países latinoamericanos se enfrascaron en asesorías exhaustivas y análisis conjuntos para estimar el impacto probable de la crisis en la región. De esa manera, en 2008 y 2009 se sostuvieron veintiocho cumbres en las distintas organizaciones regionales: Mercosur, ANCON, SICA, Caricom, ALBA, Unasur y la Alianza del Pacífico. ${ }^{77}$ Como consenso emanado de estos encuentros, se acordó que la cohesión y colaboración regionales eran fundamentales para confrontar estas condiciones adversas del exterior. En particular, los líderes latinoamericanos subrayaron la importancia de fortalecer lazos entre las diferentes iniciativas de integración. ${ }^{78}$ Con todo, en la práctica, no se ha materializado esta colaboración regional para fraguar una respuesta conjunta a la crisis. Como indica Rojas Aravena, "la tensión y la polarización del las posiciones políticas en muchos países en la región han acentuado las tendencias a la fragmentación. En este contexto, la construcción de consenso regional se ha vuelto

74 "A Continental Divide", The Economist, 18 de mayo de 2013.

75 Andrés Oppenheimer, "Dos Americas Latinas?”, La Nación, 13 de diciembre de 2011.

76 Phillips y Prieto, "The Demise of New Regionalism".

${ }^{77}$ Francisco Rojas Aravena, "The Financial Crisis: Formulating a Latin American Political Response”, V Reporte del Secretario General de Flacso, 2009.

${ }^{78}$ Rojas Aravena, "The Financial Crisis". 
más lento y difícil y requiere esfuerzos políticos y diplomáticos más grandes". ${ }^{79}$

\section{Conclusiones}

Con herramientas de las relaciones internacionales para la complejidad del régimen, este trabajo arroja luz sobre varios mecanismos con los que las interacciones de instituciones superpuestas han influido en la dinámica de cooperación en los países de América Latina. En primer lugar, la profusa fragmentación y la ambigüedad en las regulaciones de comercio permiten a los países interpretar e implementar selectivamente los acuerdos que firman. Los gobiernos latinoamericanos han solido tomar ventaja del empalme en las reglas regionales y bilaterales para esquivar compromisos y obligaciones existentes. En este sentido, la complejidad del régimen internacional ha contribuido al incumplimiento y a la implementación dispar, lo que refuerza las percepciones sobre el carácter especialmente retórico o político del regionalismo latinoamericano. En segundo lugar, los acuerdos facilitan las estrategias políticas interinstitucionales, como la elección de foros más convenientes y cambio de régimen, cosa que tiende a emplearse principalmente, si bien no exclusivamente, por Estados poderosos para aumentar su influencia en el contexto regional. En tercer lugar, la proliferación de regímenes y, en particular, la membrecía no exclusiva y superpuesta con otras ha incrementado la competencia económica y política entre Estados y agrupaciones en la región, mermando a veces la unidad y la cohesión intrarregional. De esta manera, la fragmentación institucional y la dinámica competitiva parecen haber exacerbado las visiones incompatibles de regionalismo que prevalecen desde principios de la década de 2000 dentro y a lo largo de los regímenes superpuestos en América Latina. La erosión de la unidad regional socava la capacidad de los países en la región para presentar un frente coherente en negociaciones

${ }^{79}$ Francisco Rojas Aravena, "Siete efectos políticos de la crisis internacional en América Latina”, Nueva Sociedad, 224, 2009, p. 141. 
externas, de modo que limita sus oportunidades de participar en el diseño de regímenes más amplios de gobernanza global.

Es así que en gran medida la complejidad del régimen agrava algunos de los problemas que han afectado históricamente los esfuerzos de cooperación regional en América Latina, incluidos los incentivos para el comportamiento oportunista e individualista, la competencia por el poder y la influencia regionales y la falta de solidaridad y cohesión regionales. La proliferación de acuerdos superpuestos junto con las percepciones incompatibles y las prioridades pueden entenderse -aunque no explicarse así del todocomo contribuciones a la erosión progresiva de la legitimidad del regionalismo latinoamericano sobre la que algunos especialistas han llamado la atención. Aún así, mientras que este artículo se ha concentrado en las implicaciones negativas de la complejidad del régimen, es importante considerar las oportunidades de la cooperación en aumento y la efectividad acrecentada que puede aportar la instauración de múltiples instituciones. La investigación existente sobre América Latina ha esclarecido diversos efectos de la interacción cognitiva entre instituciones regionales y multilaterales, lo que ha contribuido a la cooperación por medio de procesos de aprendizaje interinstitucional, persuasión e intercambio de información. El papel que han jugado algunas instituciones regionales, como el Banco Interamericano de Desarrollo y la CEPAL, para difundir los paradigmas normativos que conforman las políticas de integración regional y para apoyar estas estrategias, ilustra las maneras como los regímenes regionales pueden interactuar de modos que se refuercen mutuamente. ${ }^{80}$

De hecho, las implicaciones de este análisis no deben apuntar a que crear más instituciones sea algo necesariamente negativo. En cambio, el problema parece la amplia flexibilidad que los Estados siguen disfrutando en el manejo de estas instituciones y, en particular, su tendencia a manipular estas instituciones a su

${ }^{80}$ Véase, por ejemplo, EcLAc, Open Regionalism in Latin America and the Caribbean, Santiago de Chile, United Nations EcLaC Publications, 1994; y Roberto Bouzas y Peter Knaack, "The IDB and Half a Century of Regional Integration in Latin America and the Caribbean”, Integration E Trade, 29, 13, 2009, pp. 15-25. 
conveniencia. Mientras que el liderazgo del Estado es central para asegurar una articulación coherente y efectiva entre los regímenes superpuestos y paralelos, sin mayor disposición de los actores estatales para sujetarse a mecanismos institucionales, las iniciativas de cooperación latinoamericana están condenadas al fracaso. Un papel mayor para los mecanismos institucionales (en particular, en la diplomacia presidencial) es sin duda crucial dadas las extendidas asimetrías del poder que caracterizan a la región. Es esencial asimismo un mayor énfasis en la implementación, cumplimiento y coordinación para promover efectos de retroalimentación entre las instituciones superpuestas, de modo que se facilite la cooperación en el Hemisferio Occidental.

Este artículo tiene también implicaciones para dos campos de reflexión más amplios. Primero, extiende su atención más allá del trabajo existente sobre la complejidad del régimen internacional hacia la investigación de sus consecuencias en la dinámica y estabilidad de la gobernanza regional. Mientras que buena parte de la bibliografía sobre el tema ha atendido las consecuencias de incrementar la complejidad y la densidad en la calidad y la efectividad de la cooperación internacional a nivel global, se ha puesto menos atención al funcionamiento de los complejos regionales, al que caracterizan simultáneamente interacciones institucionales verticales y horizontales. En efecto, en otras regiones del mundo, como el este de Asia y África, hay sistemas complejos y superpuestos de instituciones económicas formales e informales. Al mismo tiempo, la atención que se le da a las superposiciones y otros efectos interactivos entre los acuerdos de cooperación regional contribuye a la discusión sobre regionalismo y acuerdos de comercio. Un amplio y variado grupo de especialistas ha examinado los factores detrás del resurgimiento y la proliferación de instituciones regionales en las últimas tres décadas. Con todo, mucho de este trabajo ha manejado estas iniciativas como regímenes discretos y aislados. $\mathrm{El}$ análisis en este artículo sugiere que el conocimiento de la dinámica y la evolución de la cooperación económica y política requiere de prestar atención a las consecuencias de las formas en que las instituciones interactúan entre sí. 


\section{BibLIOGRAFÍA}

“A Continental Divide”, The Economist, 18 de mayo de 2013.

Aggarwal, Vinod, Liberal Protectionism: The International Politics of Organized Textile Trade, Berkeley, University of California Press, 1985.

- Institutional Designs for a Complex World: Bargaining, Linkages, and Nesting, Ithaca, Cornell University Press, 1998.

Alter, Karen y Sophie Meunier, "The Politics of International Regime Complexity”, Perspectives on Politics, vol. 7, núm. 1, 2009, pp. 13-24.

"Astori describes Mercosur latest decisions as 'aggression and major institutional blows'”, MercoPress.com, 3 de julio de 2012.

Baldwin, Richard, "A Domino Theory of Regionalism", NBER Working Paper, 4465, 1993.

Bouzas, Roberto y Peter Knaack, "The IDB and Half a Century of Regional Integration in Latin America and the Caribbean", Integration E Trade, 29, 13, 2009, pp. 15-25.

Busch, Marc, "Overlapping Institutions, Forum Shopping and Dispute Settlement in International Trade”, International Organization, vol. 61, núm. 4, 2007, pp. 735-761.

"Chávez: Into Mercosur by a side door", Financial Times, Estados Unidos, 3 de julio de 2012.

“Costa Rica Accuses El Salvador of Violating FTA", CentralAmericaData. com, 24 septiembre de 2013.

Da Motta Veiga, Pedro y Sandra Rios, O regionalismo pós-liberal na América do Sul: Origens, iniciativas e dilemas, CEPAL, 2007. (Serie Comercio Internacional, 82)

Delich, Valentina, "Trade and Dispute Settlement in South America: Concerns and Challenges in the way to the FTAA", Integration EF Trade, 24, 2005.

Devlin, Robert y Antoni Estevadeordal, "What's New about the New Regionalism in the Americas?", en Victor Bulmer-Thomas (ed.), The Political Economy of Regionalism in Latin, Londres, Institute of Latin American Studies, 2001.

Domínguez, Jorge, "International Cooperation in Latin America: The Design of Regional Institutions by Slow Accretion", en Amitav Acharya y Alastair Johnston (eds.), Crafting Cooperation: Regional 
Interdependence in Comparative Perspective, Cambridge, Cambridge University Press, 2007.

Drezner, Daniel, "The Power and Peril of International Regime Complexity”, Perspectives on Politics, vol. 7, núm. 1, 2009.

Economic Commission for Latin America and the Caribbean, Open Regionalism in Latin America and the Caribbean, Santiago de Chile, United Nations EClac Publications, 1994.

"El Salvador Calls For Regional Support in Tariff Conflict with Costa Rica”, CentralAmericanData.com, 30 de enero de 2014.

Estevadeordal, Antoni y Kati Suominen, Bridging Regional Trade Agreements in the Americas, Washington, D. C., Inter-American Development Bank, 2009.

Ghering, Thomas y Benjamin Faude, "The Dynamics of Regime Complexes: Microfoundations and Systemic Effects", Global Governance, vol. 19, núm. 1, 2013, pp. 119-130.

Granados, Jaime y Rafael Cornejo, "Convergence in the Americas: Some Lessons from the DR-CAFTA Process”, The World Economy, vol. 29, núm. 7, 2006.

Hart-Landsberg, Martin, "Learning from ALBA and the Bank of the South", Monthly Review, 4, 2009.

Heidrich, Pablo y Diana Tussie, "Regional Trade Agreements and the wто: The Gyrating Gears of Interdependence", en Debra Steger (ed.), Redesigning the World Trade Organization for the $21^{\text {st }}$ Century, Ottawa, Wilfrid Laurier University Press, 2009.

Helfer, Laurence, "Regime Shifting in the International Intellectual Property System”, Perspectives on Politics, vol. 7, núm. 1, 2009, pp. 39-44. , "Regime Shifting: The TrIPs Agreement and New Dynamics of International Intellectual Property Lawmaking”, The Yale Journal of International Law, vol. 29, núm. 1, 2004, pp. 1-83.

Hillman, Jennifer, "Conflicts between Dispute Settlement Mechanisms in Regional Trade Agreements and the wTO- What Should the wTo Do?", Cornell International Law Journal, vol. 42, núm. 2, 2009, pp. 193-208.

Inter-American Development Bank, Beyond Borders: The New Regionalism in Latin America, Washington, D. C., Inter-American Development Bank, 2002. "Itamarati teme pelo Mercosul", Jornal do Brasil, Brasil, 26 de julio de 1999. Kuwayama, Mikio, José Durán Lima y Verónica Silva, Bilateralism and Regionalism: Reestablishing the Primacy of Multilateralism. A Latin American 
and Caribbean Perspective, Santiago, United Nations eclac Publications, 2005.

Kwak, K. y Gabrielle Marceau, "Overlaps and Conflicts of Jurisdiction between the wTo and RTAs", en Lorand Bartels y Federico Ortino (eds.), Regional Trade Agreements and the WTO Legal System, Oxford, Oxford University Press, 2006.

"La Alianza del Pacífico echa a andar en Chile", El País, 6 de junio de 2012.

Malamud, Andrés y Gian Luca Gardini, "Has Regionalism Peaked? The Latin American Quagmire and its Lessons", International Spectator: Italian Journal of International Affairs, vol. 47, núm. 1, 2012, pp.116-133.

Margulis, Matías, "The Regime Complex for Food Security: Implications for the Global Hunger Challenge”, Global Governance, 1, 2013.

McElhinny, Vincent, “CAfTA: Few Benefits, Many Costs”, en Americas Program, Interhemispheric Resource Center, Policy Brief, febrero de 2004.

"Mercosur habilitó nueva lista de excepciones", La Nación (Buenos Aires), 1 julio de 2012.

"Mercosur: Se logró superar la peor crisis", La Nación (Buenos Aires), 30 de julio de 1999.

Morin, Jean-Frédéric y Amandine Orsini, "Regime Complexity and Policy Coherence: Introducing a Co-Adjustments Model”, Global Governance, vol. 19, núm. 1, 2013, pp. 41-51.

Oberthur, Sebastian y Thomas Gehring, "Institutional Interaction: Ten Years of Scholarly Development", en Sebastian Oberthur y Olav Schram Stokke (eds.), Managing Institutional Complexity: Regime Interplay and Global Environmental Change, Cambridge, Massachusetts, MIT Press, 2011.

Oppenheimer, Andrés, “¿Dos Américas Latinas?”, La Nación (Buenos Aires), 13 de diciembre de 2011.

Orsini, Amandine, Jean-Frédéric Morin y Oran Young, "Regime Complexes: A Buzz, a Boom, or a Boost for Global Governance?”, Global Governance, vol. 19, núm. 1, 2013, pp. 27-39.

Pekkanen, Saadia, Mireya Solís y Saori Katada, "Trading Gains for Control: International Trade Forums and Japanese Economic Diplomacy", International Studies Quarterly, vol. 51, núm. 4, 2007, pp. 945-970. 
Peña, Félix, "Ni Tempo de Funerales ni Tudo Bem”, Archivos del Presente, 17, 1999.

Phillips, Nicola y G. Prieto, "The Demise of the New Regionalism: Reframing the Study of Contemporary Regional Integration in Latin America”, en Alex Warleigh-Lack, N. Robinson y Ben Rosamond (eds.), New Regionalism and the European Union. Dialogues, Comparisons and New Research Directions, Londres y Nueva York, Routledge-EcPR, 2011. Phillips, Nicola, "US Power and the Politics of Economic Governance in the Americas", en William C. Smith y Laura Gómez-Mera (eds.), Market, State, and Society in Contemporary Latin America, Malden, WilleyBlackwell, 2010.

Quiliconi, Cintia y Carol Wise, "The US as a Bilateral Player: The Impetus for Asymmetric Free Trade Agreements", en Mireya Solís, Barbara Stallings y Saori Katada (eds.), Competitive Regionalism: FTA Diffusion in the Pacific Rim, Nueva York, Palgrave, 2009.

Raustiala, Kal y David G. Victor, "The Regime Complex for Plant Genetic Resources”, International Organization, vol. 58, núm. 2, abril de 2004, pp. 277-309.

Riggirozzi, Pia, "Region, Regionness and Regionalism in Latin America:

Towards a New Synthesis" en Latin American Trade Network, Working Paper, 130, 2010.

Rojas Aravena, Francisco, "The Financial Crisis: Formulating a Latin American Political Response”, Report of Flacso's General Secretary, 5, 2009.

— Latina”, Nueva Sociedad, 224, 2009b.

Rosales, Antulio, "El Banco del Sur: (des)acuerdos sobre una arquitectura financiera alternativa", documento inédito, Universidad Central de Venezuela, 2010.

Rosales, Osvaldo, Crisis internacional y oportunidades para la cooperación Regional, CEPAL 2009. (Serie de Comercio Internacional, 93)

Rosendal, Kristin, "Impacts of Overlapping International Regimes: The Case of Biodiversity", Global Governance, 1, 2001.

Sánchez-Ancochea, Diego y Kenneth Shadlen (eds.), The Political Economy of Hemispheric Integration, Nueva York, Palgrave, 2008.

Shadlen, Kenneth, "Globalization, Power, and Integration: The Political Economy of Regional and Bilateral Trade Agreements in the Americas", Journal of Development Studies, vol. 44, núm. 1, 2008, pp. 1-20. 
Sistema Económico Latinoamericano y del Caribe, "Experiencias de cooperación monetaria y financiera en América Latina y el Caribe: balance crítico y propuestas de acción de alcance regional", $S P / D i, 10$, 2009.

Smith, James McCall, "The Politics of Dispute Settlement Design: Explaining Legalism in Regional Trade Pacts", International Organization, vol. 54, núm. 1, 2000, pp. 137-180.

Solís, Mireya, Barbara Stallings y Saori Katada (eds.), Competitive Regionalism: FTA Diffusion in the Pacific Rim, Nueva York, Palgrave, 2009.

Vacek-Aranda, Alice, "Sugar Wars: Dispute Settlement Under NAFTA and the wTo as Seen Through the Lens of the HFcs Case and its Effects on US-Mexican Relations", Texas Hispanic Journal of Law and Policy, 12, 2006.

Young, Oran, "Institutional Linkages in International Society: Polar Perspectives", Global Governance, vol. 2, núm. 1, 1996. 